\title{
Importance of Chewing Simulators in the Difference of Test Results of Dental Materials. Systematic Review
}

\author{
orlando Santiago $\mathrm{Jr}^{1}$, Marcus Vinicius Ferreira ${ }^{1}$, and Rudolf Huebner ${ }^{2}$ \\ ${ }^{1}$ Universidade Federal de Minas Gerais \\ ${ }^{2}$ Universidade Federal de Minas Gerais Escola de Engenharia
}

November 18, 2020

\begin{abstract}
Objectives: With new dental materials constantly being launched on the market, the number of researches on the properties of dental materials have increased substantially in the past few years. However different results about physical properties of the same material are frequently found in the literature. In an endeavor to elucidate the cause(s) of these disparate results, a review of the literature published in the last five years was conducted, to investigate whether these differences are due to the testing machines - also called chewing simulators - used in the studies. Data: We searched for data of indicators of test accuracy, maintenance of test parameters during all experiments, reproducibility of test and standards in the articles, or in the manufacturers' sites. Sources: The database searched was CAPES PORTAL (http://www-periodicos-capes-govbr.ez27.periodicos.capes.gov.br) Study Selection: In the search, the following keywords were used: "bite force" AND "simulator", "chewing simulator" and "mastication simulator", and the publication filter date of "January 1, 2016". As a result, 100 articles were selected and recovered in order of appearance by using the filter "relevance". Conclusion: based on the data obtained in this review, the disparate results of experiments with dental materials appeared to be more related to the test conditions rather than with the testing machines.
\end{abstract}

\section{Hosted file}

chewing simulators REV.ING190920.pdf available at https://authorea.com/users/376790/articles/ 493668-importance-of-chewing-simulators-in-the-difference-of-test-results-of-dentalmaterials-systematic-review 